\title{
Proporção entre plantas de soja e plantas competidoras e as relações de interferência mútua
}

\author{
Proportion among soybean and competitor plants and the relations of mutual interference
}

\author{
Mário Antônio Bianchi ${ }^{1}$ Nilson Gilberto Fleck ${ }^{2}$ Fabiane Pinto Lamego $^{3}$
}

\section{RESUMO}

O objetivo deste trabalho foi comparar as habilidades competitivas relativas de plantas de soja e de genótipos competidores por meio do arranjo em série de substituição. Foram realizados seis experimentos na UFRGS, em Porto Alegre-RS, em 2001 e 2002. Os tratamentos constituíram-se de cinco proporções de plantas de soja e do genótipo competidor: 100:0; 75:25; 50:50; 25:75 e 0:100. A soja foi representada pelos cultivares “IAS 5 ” $e$ "Fepagro RS 10 ” e os competidores por nabo ou pelo cultivar de soja "Fundacep 33". Os tratamentos foram dispostos em delineamento experimental inteiramente casualizado, com quatro repetições. A análise da competitividade foi efetuada por meio de diagramas aplicáveis ao arranjo de substituição e interpretação de índices de competitividade. Constatou-se que a proporção entre plantas de soja e de nabo alterou a relação de competição entre essas espécies, mas que a proporção entre plantas de soja de diferentes cultivares não modificou tal relacionamento. $O$ nabo foi mais competitivo que os genótipos de soja "IAS 5" e "Fepagro RS 10", enquanto a competitividade de "Fundacep 33” equivaleu-se à desses cultivares.

Palavras-chave: competitividade, arranjo de substituição, Raphanus sativus.

\section{ABSTRACT}

The objective of this study was to compare the competitive abilities of soybean plants with those of competitor genotypes through the design of replacement series. There were performed six experiments at UFRGS, in Porto Alegre - RS, in 2001 and 2002. The treatments tested were five proportions of plants among soybean and competitor genotypes: 100:0; 75:25; 50:50; 25:75; and 0:100. Soybean was represented by the cultivars 'IAS 5' and 'Fepagro RS 10', and the competitors

\begin{abstract}
by forage radish or by the soybean cultivar 'Fundacep 33'. The treatments were arranged in a completely random experimental design, with four replications. The competitivity analysis was accomplished through diagrams applicable to the substitutive design and interpretation of competitive indexes. It was proved that the proportion among soybean plants and forage radish plants changed the competition relation among these species, but that the proportion among soybean plants from different cultivars did not altered such relationship. Radish was more competitive than the soybean cultivars 'IAS 5' and 'Fepagro RS 10', whereas the competitivity of 'Fundacep 33' genotype was equivalent to these cultivars.
\end{abstract}

Key words: competitivity, substitutive design, Raphanus sativus.

\section{INTRODUÇÃO}

A habilidade de uma espécie em competir com outra relaciona-se a vários fatores, dentre eles destacam-se espécie vegetal, densidade populacional e época de emergência de uma espécie em relação a outra e características de planta. Plantas daninhas, por serem espécies de ocorrência espontânea, possuem variabilidade genética que lhes garante maior oportunidade de adaptação ao ambiente competitivo do que espécies cultivadas selecionadas pelo homem. Além disso, em áreas agrícolas, geralmente elas ocorrem em densidades bem superiores às das espécies cultivadas. Por esses motivos, espécies daninhas são, freqüentemente, rotuladas como mais competitivas que

${ }^{1}$ Fundação Centro de Experimentação e Pesquisa (FUNDACEP). CP 10, 98100-970, Cruz Alta, RS, Brasil. E-mail: mariobianchi@fundacep.com.br. Autor para correspondência.

${ }^{2}$ Departamento de Plantas de Lavoura, Faculdade de Agronomia, Universidade Federal do Rio Grande do Sul (UFRGS), Porto Alegre, RS, Brasil.

${ }^{3}$ Programa de Pós-graduação em Fitotecnia, Faculdade de Agronomia, UFRGS, Porto Alegre, RS, Brasil. 
as cultivadas. Contudo, a densidade em que uma espécie daninha normalmente ocorre em lavouras encobre sua real habilidade em competir e, desse modo, pode-se inferir que ela apresente habilidade competitiva superior, quando, na realidade, o efeito decorre da densidade. Para esclarecer as relações competitivas entre espécies, comumente são utilizados experimentos substitutivos convencionais (ROUSH et al., 1989).

Em experimentos substitutivos, a densidade total das plantas é mantida constante, mas a proporção dos genótipos varia desde a monocultura de um até a monocultura do outro participante. Esses experimentos visam a indicar qual genótipo ou espécie é mais competitivo (COUSENS, 1991). Experimentos substitutivos também são utilizados para caracterizar a competitividade entre culturas comerciais, permitindo escolher a combinação de espécies que possibilite maior produção por área (GHOSH, 2004) e maior supressão de plantas daninhas (BAUMANN et al., 2000). A hierarquia competitiva entre espécies cultivadas $\mathrm{e}$ daninhas também pode ser determinada por esse tipo de experimento (ROUSH et al., 1989; PANTONE \& BAKER, 1991; PASSINI, 2001).

$\mathrm{Na}$ maioria dos casos, experimentos substitutivos demonstram que a cultura é mais competitiva do que a espécie daninha, porque o efeito das infestantes em culturas não se deve à maior habilidade competitiva individual delas, mas sim ao seu grau de infestação e à densidade total (VILÀ et al., 2004; ROUSH et al., 1989). A cevada é mais competitiva que a Lolium rigidum (Gaud.) porque o afilhamento precoce da cultura em relação ao $\mathbf{L}$. rigidum gera maior demanda pelo nitrogênio do solo, tornando-a mais competitiva não pela absorção mais rápida de nitrogênio, mas pela antecipação na sua demanda por esse nutriente (PONCE, 1998). Por prover informação sobre os mecanismos envolvidos na competição, o conhecimento advindo de experimentos substitutivos torna possível desenvolver práticas mais eficientes de manejo de plantas daninhas.

Em espécies aparentadas, no entanto, a vantagem não está necessariamente do lado da cultura comercial. Nesse sentido, embora o sorgo seja mais competitivo que o Sorghum halepense (L.) Pers. (sorgode-alepo) e biótipo daninho derivado do sorgo (HOFFMAN \& BUHLER, 2002), o arroz-vermelho é competidor superior quando cresce junto com o arroz cultivado (PANTONE \& BAKER, 1991).

A espécie daninha Solanum ptycanthm L. cresce mais na proporção de $75 \%$ da soja para $25 \%$ da planta daninha que quando cultivada em monocultura. Isto se deve à maior disponibilidade de nitrogênio no solo na presença de soja e à responsividade de $\boldsymbol{S}$. ptycanthum a esse nutriente (CROTSER \& WITT, 2000).
Evitar a competição é uma estratégia que propicia maior crescimento de uma espécie sem que haja prejuízo da outra, ou que leva ambas as espécies a crescerem mais. Em soja, Anoda cristata (L.) Schlecht. (malva-de-crista), Euphorbia heterophylla L. (leiteira) e Ipomoea ramosissima (Poir.) Choysy (corda-de-viola) evitam, ao menos em parte, a competição com a cultura (PURICELLI et al., 2003; RIZZARDI et al., 2004).

Nesta pesquisa, testou-se a hipótese de que plantas da mesma espécie exercem maior competição pelos recursos do ambiente porque exploram o mesmo nicho ecológico. O objetivo desse trabalho foi investigar as habilidades competitivas relativas de plantas de soja e de genótipos competidores por meio do método experimental de séries substitutivas.

\section{MATERIAL E MÉTODOS}

Foram realizados seis experimentos na Faculdade de Agronomia da Universidade Federal do Rio Grande do Sul, em Porto Alegre-RS. De novembro a dezembro de 2001, conduziram-se os Ensaios I e II; de outubro a novembro de 2002, os Ensaios III e IV; e, de dezembro de 2002 a janeiro de 2003, os Ensaios V e VI. Os tratamentos testados foram proporções de plantas do genótipo $\mathrm{X}$ (soja) e do genótipo $\mathrm{Y}$ (competidor): 100:0 (monocultura de soja); 75:25; 50:50; 25:75 e 0:100 (monocultura do competidor). A soja foi representada pelos cultivares "IAS 5" nos Ensaios I, III e V e "Fepagro RS 10” (RS 10) nos Ensaios II, IV e VI, e os competidores por Raphanus sativus L. (nabo) nos Ensaios I, II, III e IV ou pelo cultivar de soja “Fundacep 33” nos Ensaios V e VI. Os tratamentos resultantes dessas combinações foram dispostos em delineamento experimental inteiramente ao acaso, com quatro repetições. Foram escolhidos os cultivares de soja "IAS 5" e "RS 10" por apresentarem estatura de planta e ciclo de crescimento contrastantes e, como competidores, o nabo e a própria soja. O nabo é uma espécie daninha que ocorre em lavouras de soja e mostra germinação e emergência mais uniformes que espécies daninhas típicas; em decorrência disso, a cultura é submetida à pressão de competição uniforme. Já a soja cultivar “Fundacep 33”, por pertencer à mesma espécie vegetal, tende a ocupar o mesmo nicho ecológico, podendo exercer elevada pressão de competição.

Os experimentos foram realizados em vasos plásticos com capacidade para 8L (em 2001) ou 10L (em 2002), ambos com $25 \mathrm{~cm}$ de altura. O solo utilizado para preencher os vasos apresentou, em média, as seguintes características físico-químicas: $24 \%$ de argila; $2 \%$ de matéria orgânica; $\mathrm{pH}$ em água 5,5; P 40 $\mathrm{mg} \mathrm{L}^{-1}$; K 140mg $\mathrm{L}^{-1}$ e saturação de bases de $60 \%$. Dez dias após a 
semeadura, foi efetuado desbaste de plântulas, deixando-se as oito plantas mais vigorosas em cada vaso, equivalendo a uma população de 208 plantas $\mathrm{m}^{-2}$ em vasos com capacidade para 8L e a 176 plantas $\mathrm{m}^{-2}$ em vasos com capacidade para 10L.

Aos 42 dias após a emergência (DAE), foram determinados a estatura, o número de nós, a área foliar, a massa da matéria seca foliar (MF), representada esta pelos folíolos sem os pecíolos, a massa da parte aérea (MPA) das plantas de soja e a MPA das plantas de nabo. A MF e a MPA foram obtidas pela pesagem da matéria vegetal após ser secada em estufa à $65^{\circ} \mathrm{C}$ por três dias.

Para analisar a MPA da cultura e do competidor, foi utilizado o método da análise gráfica da produtividade relativa (RADOSEVICH, 1987; ROUSH et al., 1989; COUSENS, 1991). Esse procedimento, também chamado de método convencional para experimentos substitutivos, consiste na construção de um diagrama com base na produtividade relativa (PR) e na produtividade relativa total (PRT) nas proporções 0, 25, 50, 75 e 100\% do genótipo X e do Y. A produtividade relativa é calculada da seguinte forma: $\mathrm{PR}=$ MPA média da mistura / MPA média da monocultura, considerando-se no cálculo a MPA média por planta do genótipo em cada vaso. Nesses diagramas, os resultados obtidos são comparados com os valores de uma reta hipotética, a qual une os pontos zero e 100 do diagrama, que representa a ausência de interferência de um genótipo sobre o outro. A PRT é representada pela soma da $\mathrm{PR}$ da cultura e do competidor nas respectivas proporções.

Além da PR e da PRT, foram calculados os índices competitividade relativa (CR), coeficiente de agrupamento relativo (K) e agressividade (A). A CR representa o crescimento comparativo do genótipo $\mathrm{X}$ em relação ao Y; K indica a dominância relativa de um genótipo sobre o outro; e A aponta qual dos genótipos é mais agressivo. Esses índices interpretados em conjunto indicam com mais segurança qual genótipo manifesta-se mais competitivo (COUSENS, 1991). Os índices CR, K e A foram calculados para a proporção 50:50, utilizando-se as equações sugeridas por COUSENS \& O'NEILL (1993): $\mathrm{CR}=\mathrm{PR}_{\mathrm{x}} / \mathrm{PR}_{\mathrm{y}} ; \mathrm{K}_{\mathrm{x}}=\mathrm{PR}_{\mathrm{x}} /$ $\left(1-\mathrm{PR}_{\mathrm{x}}\right) ; \mathrm{K}_{\mathrm{y}}=\mathrm{PR}_{\mathrm{y}} /\left(1-\mathrm{PR}_{\mathrm{y}}\right) ; \mathrm{A}=\mathrm{PR}_{\mathrm{x}}-\mathrm{PR}_{\mathrm{y}}$. Para realizar análise estatística da produtividade relativa, inicialmente calculou-se a diferença para os valores de PR (DPR) obtidos nas proporções 25, 50 e 75\% em relação aos valores pertencentes à reta hipotética nas respectivas proporções, quais sejam, 0,25, 0,50 e 0,75 para PR (PASSINI, 2001). Utilizou-se o teste " $\mathrm{t}$ " para testar diferenças nos índices DPR, PRT, CR, K e A(ROUSH et al., 1989; HOFFMAN \& BUHLER, 2002). Considerouse, como hipótese nula para testar DPR e A, que as médias fossem iguais a zero; para PRT e CR, que as médias fossem iguais a 1; e, para $\mathrm{K}$, que as médias das diferenças entre $K_{x}$ e $K_{y}$ fossem iguais a zero. O critério adotado para se considerar as curvas de PR e PRT diferentes das retas hipotéticas foi que, no mínimo em duas proporções, ocorresse diferença significativa pelo teste "t". Para os índices CR, K e A, considerou-se existência de diferença em competitividade quando, no mínimo em dois deles, houvesse diferença significativa pelo teste " $\mathrm{t}$ ".

Os resultados obtidos para estatura de planta, número de nós, área foliar e matéria seca foliar, expressos em valores médios por planta, foram submetidos à análise de variância, com uso do programa computacional SAS (SAS, 1989). Quando a estatística F indicou significância, as médias dos tratamentos foram comparadas pelo teste de Dunnett, considerando-se as monoculturas como testemunhas. Em todas as análises estatísticas adotou-se 5\% de probabilidade de erro.

\section{RESULTADOS E DISCUSSÃO}

A análise gráfica dos experimentos substitutivos mostra que os desvios observados das retas de produtividade relativa, em relação às retas esperadas, foram mais expressivos quando o competidor foi nabo (Ensaios I a IV) que quando o competidor foi soja “Fundacep 33” (Ensaios V e VI) (Figura 1). Nota-se, também, que nos Ensaios I a IV, as PR do nabo são representadas por linhas convexas, enquanto as PR de soja o são por linhas côncavas. Isso significa que a interação dos genótipos dá-se pelo mesmo recurso do ambiente, de modo que uma espécie utiliza recurso do meio de forma mais eficiente que outra. Nesse caso, o nabo foi mais agressivo que a soja. Esse comportamento mostra que uma espécie é mais agressiva que a outra e contribui mais que o esperado para o rendimento total (RADOSEVICH, 1987).

Dentre os experimentos efetuados com nabo, as diferenças de PR, comparativamente às produtividades equivalentes, foram significativas nos Ensaios I, III e IV (Tabela 1). No Ensaio I, os desvios de DPR foram significativos para nabo; no Ensaio III, as diferenças foram significativas tanto para soja "IAS 5" como para nabo; e, no Ensaio IV, foi significativo para o cultivar "RS 10" no arranjo soja:competidor de 50:50 e de 25:75. Nesses experimentos, nota-se que o cultivar "RS 10", embora tenha tido sua PR reduzida pela presença do nabo, proporcionalmente causou maior prejuízo no crescimento relativo do competidor do que 

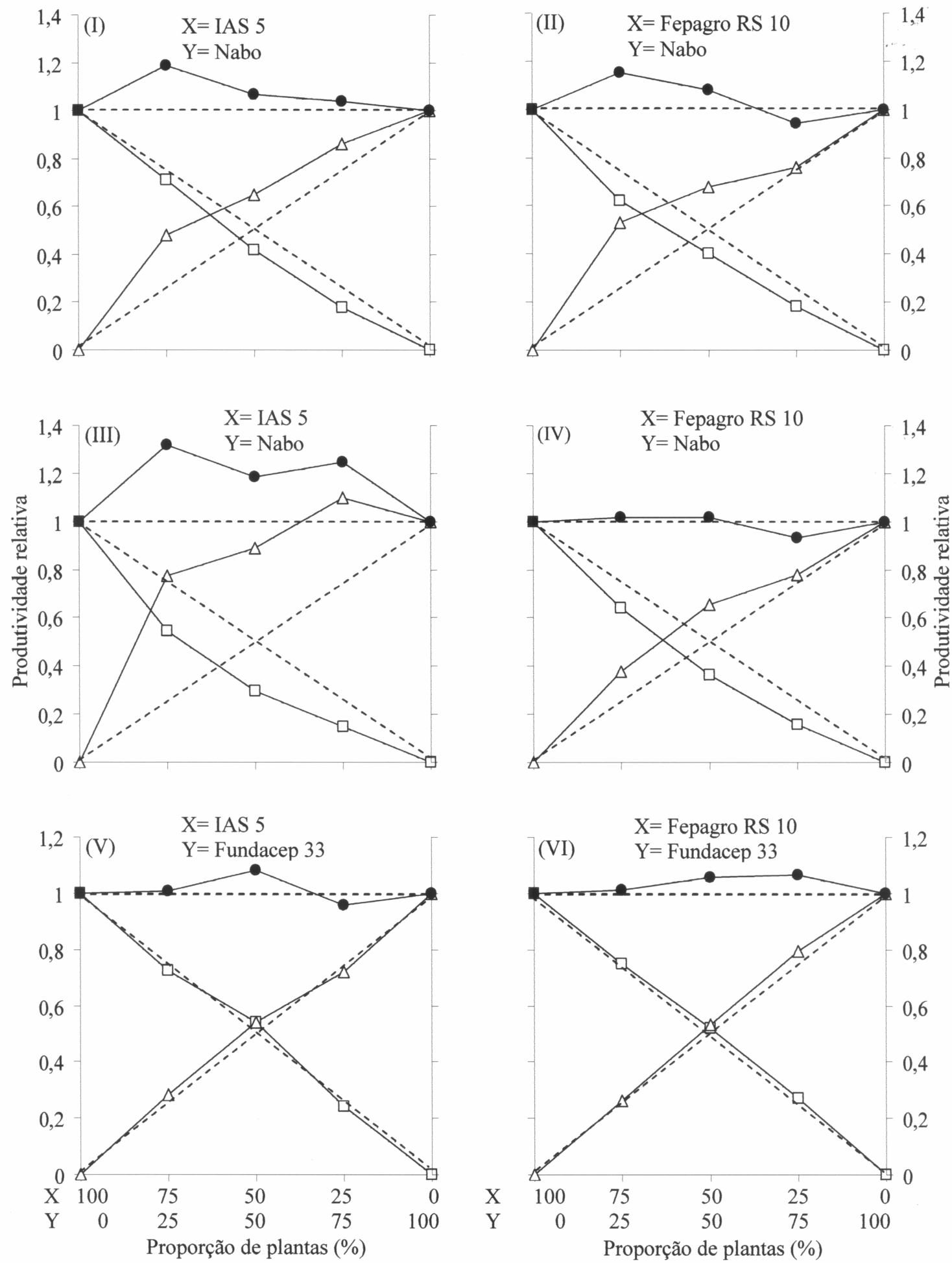

Figura 1 - Diagramas resultantes dos Ensaios I a VI (números entre parênteses), conduzidos como séries de substituição, UFRGS, Porto Alegre-RS, 2002. Símbolos quadrados $(\boldsymbol{\square})$ representam a produtividade relativa da soja $(X)$, triângulos $(\boldsymbol{\Delta})$ a do competidor $(\mathrm{Y})$ e círculos $(\bullet)$ a produtividade relativa total. As linhas tracejadas referem-se às produtividades relativas hipotéticas, nas quais não ocorre interferência de um genótipo sobre o outro. 
Tabela 1 - Diferenças de produtividade relativa (DPR) e de produtividade relativa total (PRT), nas proporções 75:25, 50:50 e 25:75, respectivamente, de soja (“IAS 5" ou "Fepagro RS 10") e de competidor (nabo ou soja "Fundacep 33"), aos 42 dias após a emergência da soja, UFRGS, Porto Alegre-RS, 2002

\begin{tabular}{lccc}
\hline & & Proporções de plantas (soja:competidor) & \\
\cline { 2 - 4 } & \multicolumn{1}{c}{$75: 25$} & $50: 50$ & $25: 75$ \\
\hline Ensaio I & & & $-0,07( \pm 0,02)^{\mathrm{ns}}$ \\
DPR IAS 5 & $-0,04( \pm 0,05)^{\mathrm{ns}}$ & $-0,08( \pm 0,02)^{*}$ & $0,11( \pm 0,06)^{\mathrm{ns}}$ \\
DPR Nabo & $0,23( \pm 0,06)^{*}$ & $0,15( \pm 0,04)^{*}$ & $1,04( \pm 0,06)^{\mathrm{ns}}$ \\
PRT & $1,19( \pm 0,07)^{\mathrm{ns}}$ & $1,07( \pm 0,05)^{\mathrm{ns}}$ & $-0,07( \pm 0,02)^{\mathrm{ns}}$ \\
Ensaio II & & & $0,01( \pm 0,02)^{\mathrm{ns}}$ \\
DPR RS 10 & $-0,13( \pm 0,05)^{\mathrm{ns}}$ & $-0,09( \pm 0,02)^{*}$ & $0,95( \pm 0,03)^{\mathrm{ns}}$ \\
DPR Nabo & $-0,28( \pm 0,01)^{*}$ & $0,18( \pm 0,07)^{\mathrm{ns}}$ & $-0,10( \pm 0,02)^{*}$ \\
PRT & $1,15( \pm 0,06)^{\mathrm{ns}}$ & $1,09( \pm 0,07)^{\mathrm{ns}}$ & $0,35( \pm 0,14)^{\mathrm{ns}}$ \\
Ensaio III & & & $1,25( \pm 0,12)^{\mathrm{ns}}$ \\
DPR IAS 5 & $-0,21( \pm 0,02)^{*}$ & $-0,20( \pm 0,01)^{*}$ & $-0,09( \pm 0,02)^{*}$ \\
DPR Nabo & $0,53( \pm 0,04)^{*}$ & $0,39( \pm 0,02)^{*}$ & $0,03( \pm 0,03)^{\mathrm{ns}}$ \\
PRT & $1,32( \pm 0,04)^{*}$ & $1,19( \pm 0,02)^{*}$ & $0,93( \pm 0,02)^{\mathrm{ns}}$ \\
Ensaio IV & & $-0,14( \pm 0,01)^{* *}$ & $-0,01( \pm 0,00)^{\mathrm{ns}}$ \\
DPR RS 10 & $-0,11( \pm 0,05)^{\mathrm{ns}}$ & $0,15( \pm 0,06)^{\mathrm{ns}}$ & $-0,03( \pm 0,01)^{\mathrm{ns}}$ \\
DPR Nabo & $0,13( \pm 0,05)^{\mathrm{ns}}$ & $1,02( \pm 0,07)^{\mathrm{ns}}$ & $0,96( \pm 0,01)^{\mathrm{ns}}$ \\
PRT & $1,02( \pm 0,04)^{\mathrm{ns}}$ & & $0,02( \pm 0,02)^{\mathrm{ns}}$ \\
Ensaio V & & $0,04( \pm 0,05)^{\mathrm{ns}}$ & $0,05( \pm 0,02)^{\mathrm{ns}}$ \\
DPR IAS 5 & $-0,03( \pm 0,01)^{\mathrm{ns}}$ & $0,04( \pm 0,02)^{\mathrm{ns}}$ & $1,07( \pm 0,02)^{\mathrm{ns}}$ \\
DPR Fundacep 33 & $0,03( \pm 0,01)^{*}$ & $1,08( \pm 0,05)^{\mathrm{ns}}$ & \\
PRT & $1,01( \pm 0,02)^{\mathrm{ns}}$ & $0,02( \pm 0,01)^{\mathrm{ns}}$ & $0,03( \pm 0,02)^{\mathrm{ns}}$ \\
Ensaio VI & $0,00( \pm 0,05)^{\mathrm{ns}}$ & $1,05( \pm 0,03)^{\mathrm{ns}}$ & \\
DPR RS 10 & $0,01( \pm 0,02)^{\mathrm{ns}}$ & & \\
DPR Fundacep 33 & $1,01( \pm 0,07)^{\mathrm{ns}}$ & & \\
PRT & & & \\
\hline
\end{tabular}

Diferença não significativa ${ }^{(\mathrm{ns})}$ e significativa ${ }^{(*)}$ a $5 \%$ de probabilidade do erro pelo teste “t”. Valores entre parênteses representam o erro padrão da média.

o fez o cultivar "IAS 5". Isso sugere que o cultivar "RS 10 ” possui maior poder de supressão do nabo que o cultivar "IAS 5".

As variáveis morfológicas também reforçam o fato de o nabo exercer maior interferência sobre o cultivar "IAS 5" que sobre "RS 10" (Tabela 2). Embora tenham ocorrido reduções significativas em estatura de planta e área foliar para o cultivar "RS 10" nos Ensaios II e IV, elas ocorreram em alguns casos quando a proporção de soja foi inferior à de nabo. No entanto, no Ensaio III, quando houve predomínio de plantas de soja (proporção 75:25), o cultivar “IAS 5” apresentou redução na estatura de planta e área foliar. Já o cultivar "RS 10" somente reduziu essas variáveis a partir de menores proporções de soja. Esses resultados indicam que o cultivar "RS 10" apresenta maior tolerância à competição com nabo do que "IAS 5".

Nos Ensaios V e VI, em que o cultivar “Fundacep 33” foi o competidor, não houve diferenças significativas em PR dos cultivares de soja, em relação às produtividades equivalentes (Tabela 1 ), o que significa que não há efeito de uma espécie sobre a outra ou que a habilidade das espécies em interferir uma sobre a outra é equivalente (RADOSEVICH, 1987). Nesses experimentos, também não ocorreram diferenças para número de nós, estatura de planta e matéria seca foliar dos cultivares de soja (Tabela 2). Isso indica que os genótipos de soja mostraram habilidades competitivas basicamente equivalentes. Mesmo que eles apresentem características diferentes, como estatura de planta, capacidade de ramificação e matéria seca, os cultivares de soja testados nos Ensaios V e VI possuem elevado grau de parentesco. Isto explica, em parte, porque eles se equivaleram em competitividade. De outro lado, como os ensaios foram encerrados aos 42 DAE, outras eventuais diferenças, como seu ciclo de crescimento, não tiveram tempo suficiente para se manifestarem em sua plenitude. 
Tabela 2 - Resposta de cultivares de soja, expressa em número de nós, estatura (cm), área foliar $\left(\mathrm{cm}^{2}\right.$ planta $\left.{ }^{-1}\right)$ e matéria seca foliar (mg planta $^{-1}$ ), à interferência do competidor (nabo ou soja cultivar “Fundacep 33”) em ensaios conduzidos em séries substitutivas, aos 42 dias após a emergência da soja, UFRGS, Porto Alegre-RS, 2002.

\begin{tabular}{|c|c|c|c|c|c|c|}
\hline & \multicolumn{5}{|c|}{ Proporções de plantas (soja:competidor) } & \multirow{2}{*}{$\begin{array}{l}\text { Coeficientes de } \\
\text { variação (\%) }\end{array}$} \\
\hline & 100:0 (T) & $75: 25$ & $50: 50$ & $25: 75$ & $0: 100(\mathrm{~T})$ & \\
\hline \multicolumn{7}{|l|}{ Número de nós } \\
\hline Ensaio I - IAS 5 & $3,1^{\mathrm{ns}}$ & 2,6 & 2,6 & 2,2 & - & 15 \\
\hline Ensaio II - Fepagro RS 10 & 3,8 & $3,0^{*}$ & $2,8^{*}$ & 3,2 & - & 12 \\
\hline Ensaio III - IAS 5 & $6,8^{\mathrm{ns}}$ & 6,2 & 5,9 & 5,9 & - & 9 \\
\hline Ensaio IV - Fepagro RS 10 & $6,5^{\text {ns }}$ & 6,2 & 6,2 & 6,1 & - & 6 \\
\hline Ensaio V - IAS 5 & $6,8^{\text {ns }}$ & 6,8 & 6,6 & 6,9 & - & 5 \\
\hline Ensaio V - Fundacep 33 & - & 6,8 & 6,8 & 6,5 & $6,4^{\mathrm{ns}}$ & 4 \\
\hline Ensaio VI - Fepagro RS 10 & $6,6^{\mathrm{ns}}$ & 6,8 & 6,9 & 6,6 & - & 3 \\
\hline Ensaio VI - Fundacep 33 & - & 6,6 & 6,6 & 6,8 & $6,8^{\mathrm{ns}}$ & 6 \\
\hline \multicolumn{7}{|l|}{ Estatura de planta } \\
\hline Ensaio I - IAS 5 & $12,6^{\mathrm{ns}}$ & 12,7 & 11,7 & 11,7 & - & 9 \\
\hline Ensaio II - Fepagro RS 10 & 15,0 & 14,2 & 13,6 & $12,6^{*}$ & - & 8 \\
\hline Ensaio III - IAS 5 & 24,5 & $22,3^{*}$ & $21,6^{*}$ & $19,9 *$ & - & 3 \\
\hline Ensaio IV - Fepagro RS 10 & 29,1 & 27,0 & $25,3^{*}$ & $22,9 *$ & - & 5 \\
\hline Ensaio V - IAS 5 & $26,2^{\mathrm{ns}}$ & 26,6 & 28,2 & 25,9 & - & 8 \\
\hline Ensaio V - Fundacep 33 & - & 32,2 & 33,1 & 31,5 & $32,1^{\mathrm{ns}}$ & 4 \\
\hline Ensaio VI - Fepagro RS 10 & $29,6^{\mathrm{ns}}$ & 29,3 & 29,4 & 29,5 & - & 4 \\
\hline Ensaio VI - Fundacep 33 & - & 32,2 & 32,4 & 33,0 & $32,8^{\text {ns }}$ & 6 \\
\hline \multicolumn{7}{|l|}{ Área folhar } \\
\hline Ensaio I - IAS 5 & $98^{\text {ns }}$ & 88 & 78 & 73 & - & 15 \\
\hline Ensaio II - Fepagro RS 10 & 105 & 82 & $80 *$ & $67 *$ & - & 15 \\
\hline Ensaio III - IAS 5 & 1065 & $771^{*}$ & $614^{*}$ & $642 *$ & - & 17 \\
\hline Ensaio IV - Fepagro RS 10 & 1189 & 1028 & $886^{*}$ & $801^{*}$ & - & 14 \\
\hline \multicolumn{7}{|l|}{ Matéria seca folhar } \\
\hline Ensaio V - IAS 5 & $1066^{\text {ns }}$ & 1068 & 1104 & 1046 & - & 10 \\
\hline Ensaio V - Fundacep 33 & - & $1159 *$ & 1095 & 998 & 1018 & 7 \\
\hline Ensaio VI - Fepagro RS 10 & $1092^{\mathrm{ns}}$ & 1113 & 1169 & 1230 & - & 11 \\
\hline Ensaio VI - Fundacep 33 & - & 1078 & 1039 & 1035 & $978^{\mathrm{ns}}$ & 12 \\
\hline
\end{tabular}

Diferença não significativa ${ }^{\text {(ns) }}$ e significativa ${ }^{(*)}$ em relação à testemunha $(\mathrm{T})$ pelo teste de Dunnett a $5 \%$ de probabilidade do erro.

Quando o nabo foi espécie competidora, a PRT foi equivalente a 1 nos Ensaios I, II e IV, e superior a 1 no Ensaio III; e, quando a soja "Fundacep 33" foi competidor, a PRT foi sempre equivalente a 1 (Figura 1 , Tabela 1). Isso significa que, em geral, na presença de nabo, ocorreu competição pelos mesmos recursos do ambiente. Por outro lado, na presença de "Fundacep 33", tanto "IAS 5" como "RS 10" apresentaram PR e PRT equivalentes a 1 , denotando ausência de competição ou competição pelos mesmos recursos do ambiente na mesma proporção.

O crescimento relativo do nabo foi maior na proporção de $75 \%$ de soja para $25 \%$ do competidor em três (Ensaios I, II e III) dos quatro experimentos realizados (Figura 1; Tabela 1). Este comportamento foi semelhante ao verificado por CROTSER \& WITT (2000) com a espécie daninha $S$. ptycanthum. Possivelmente, o nitrogênio do solo ficou disponível em maior quantidade na menor proporção de nabo. Devido à soja absorver nitrogênio por meio da fixação simbiótica com rizóbio, quanto menor for a proporção de plantas de nabo maior será a disponibilidade do elemento por indivíduo; conseqüentemente, maior será o crescimento esperado do competidor. Verificou-se, também, que ocorreu menor crescimento relativo da soja nos Ensaios III e IV (Figura 1). Possivelmente, devido à nodulação da soja ainda não suprir toda a necessidade da cultura, a maior demanda de nitrogênio pelo nabo resultou em competição por fração de nitrogênio disponível no solo, reduzindo o crescimento da cultura. Ademais, se o nabo favoreceu-se da maior disponibilidade relativa de nitrogênio, cresceu mais e possivelmente sombreou mais a soja.

O crescimento da soja em relação ao nabo, indicado pelo índice CR, foi inferior ao do competidor nos Ensaios I, II, III e IV (Tabela 3). Adicionalmente, 
Tabela 3 - Índices de competitividade entre soja e competidor, expressos por competitividade relativa, coeficientes de agrupamento relativo e de agressividade, obtidos em seis ensaios conduzidos em séries substitutivas, UFRGS, Porto Alegre-RS, 2002

\begin{tabular}{|c|c|c|c|c|}
\hline & \multirow{2}{*}{$\begin{array}{l}\text { Competitividade relativa } \\
\text { (CR) }\end{array}$} & \multicolumn{2}{|c|}{ Coeficientes de agrupamento relativo (K) } & \multirow{2}{*}{ Agressividade (A) } \\
\hline & & $\mathrm{K}_{\mathrm{x}}$ (soja) & $\mathrm{K}_{\mathrm{y}}$ (competidor) & \\
\hline Ensaio I & $0,64( \pm 0,08)^{*}$ & $0,72( \pm 0,06)$ & $1,95( \pm 0,30)^{*}$ & $-0,24( \pm 0,03)^{*}$ \\
\hline Ensaio II & $0,62( \pm 0,09)^{*}$ & $0,69( \pm 0,06)$ & $1,78( \pm 0,32)^{*}$ & $-0,28( \pm 0,07)^{\mathrm{ns}}$ \\
\hline Ensaio III & $0,33( \pm 0,02)^{*}$ & $0,42( \pm 0,02)$ & $9,04( \pm 1,47)^{*}$ & $-0,60( \pm 0,03)^{*}$ \\
\hline Ensaio IV & $0,57( \pm 0,06)^{*}$ & $0,57( \pm 0,03)$ & $1,46( \pm 0,12)^{*}$ & $-0,29( \pm 0,07)^{*}$ \\
\hline Ensaio V & $1,00( \pm 0,09)^{\mathrm{ns}}$ & $1,26( \pm 0,28)$ & $1,19( \pm 0,10)^{\mathrm{ns}}$ & $0,00( \pm 0,05)^{\mathrm{ns}}$ \\
\hline Ensaio VI & $0,98( \pm 0,02)^{\mathrm{ns}}$ & $1,09( \pm 0,05)$ & $1,15( \pm 0,07)^{\mathrm{ns}}$ & $0,01( \pm 0,01)^{\mathrm{ns}}$ \\
\hline
\end{tabular}

Ensaios I e III: “IAS 5” x Nabo; Ensaios II e IV: “Fepagro RS 10” x Nabo; Ensaio V: “IAS 5” x “Fundacep 33” e Ensaio VI: “Fepagro RS 10 ” x "Fundacep 33”.

Diferença não significativa $^{(\mathrm{ns})}$ e significativa ${ }^{(*)}$ a $5 \%$ de probabilidade do erro pelo teste “t”. Valores entre parênteses representam o erro padrão da média.

houve dominância do nabo sobre a soja cultivar "IAS 5” (Ensaios I e III) e sobre o cultivar "RS 10” no Ensaio II, conforme indica o índice K; e, ainda, constatou-se o nabo como sendo mais agressivo que a soja "IAS 5" por meio do índice A. Nos Ensaios V e VI, não houve diferenças nas comparações referentes aos índices de competitividade.

$\mathrm{O}$ genótipo $\mathrm{X}$ é mais competitivo que $\mathrm{Y}$ quando $\mathrm{CR}>1, \mathrm{~K}_{\mathrm{x}}>\mathrm{K}_{\mathrm{y}}$ eA $>0$ (HOFFMAN \& BUHLER, 2002). Levando-se em conta que, para mostrar superioridade competitiva, o genótipo deve apresentar diferença significativa pelo menos em dois índices, o nabo revelou-se mais competitivo que os cultivares de soja "IAS 5" (Ensaios I e III) e "RS 10" (Ensaio II). Utilizando esses três índices de competitividade, HOFFMAN \& BUHLER (2002) verificaram que o sorgo foi mais competitivo que o $S$. halepense.

Supostamente, por explorar o mesmo nicho ecológico, esperava-se que os genótipos de soja competissem pelos mesmos recursos do ambiente, apresentando diferenças acentuadas em competitividade. Tais diferenças verificam-se comumente em espécies aparentadas, como, por exemplo, entre arroz e arroz-vermelho (PANTONE \& BAKER, 1991) e entre sorgo e sorgo-de-alepo ou entre sorgo e biótipo silvestre originado do sorgo cultivado (HOFFMAN \& BUHLER, 2002). Uma possível causa para ocorrer competitividade equivalente entre espécies ou genótipos afins é que a densidade de plantas por área não tenha sido suficiente para atingir máxima produção de matéria seca pela comunidade (JOLLIFFE et al., 1984).

No entanto, no caso dos ensaios relatados, a densidade foi equivalente a aproximadamente cinco vezes aquela indicada para o cultivo de soja em lavouras. Além disso, existe pouca evidência de mudanças qualitativas em experimentos substitutivos com o aumento da densidade, ou seja, a dominância de uma espécie sobre a outra raramente muda com a alteração da densidade (COUSENS \& O’NEILL, 1993). Contudo, o aumento de densidade pode conduzir a mudanças quantitativas, ou seja, à alteração na intensidade de determinado índice de competitividade. Outra explicação é a de que maiores diferenças entre os cultivares de soja possivelmente surgissem caso as plantas crescessem sob interferência até a maturação. Adicionalmente, durante o período experimental, é possível que as plantas de soja tenham sido supridas com recursos de solo suficientes ao crescimento, evitando a competição direta.

Tomadas em conjunto, as análises gráficas de produtividade relativa e sua significância em relação às produtividades equivalentes, às variáveis morfológicas e aos índices de competitividade, verificase que houve interferência do nabo sobre os cultivares de soja "IAS 5" e "RS 10", sendo aquele mais competitivo que estes. Nos experimentos em que cultura e competidor constituíram-se de genótipos de soja, não se observaram diferenças gráficas ou estatísticas que pudessem indicar que um genótipo fosse mais competitivo que o outro, sendo atribuídas aos cultivares “IAS 5" e "RS 10" habilidades competitivas equivalentes às do “Fundacep 33”. Explorar o mesmo nicho ecológico não resultou em perdas por competição entre plantas dos cultivares de soja “Fundacep 33”, “IAS 5” e "RS 10”.

A competição de soja com nabo ocorreu basicamente por recurso comum encontrado no ambiente de crescimento, mesmo que, no Ensaio III, o nabo tenha sido indiferente à competição. As diferenças 
morfofisiológicas existentes entre cultivares de soja “IAS 5”, "RS 10” e “Fundacep 33” foram insuficientes para imprimir, durante o período experimental considerado, competição diferencial por recursos do ambiente e, conseqüentemente, caracterizar variações expressivas em competitividade entre tais genótipos. De outro modo, nos experimentos em que o nabo se constituiu no competidor, não foi possível identificarse o recurso pelo qual os genótipos competiram. Especula-se que a interferência tenha ocorrido por nutrientes do solo, principalmente pelo nitrogênio, mas não se pode descartar até mesmo efeito de alelopatia do nabo sobre a soja.

\section{CONCLUSÕES}

Durante a fase vegetativa de crescimento da cultura, a proporção entre plantas de soja e de nabo altera as relações de competição entre as espécies, sendo que o nabo exerce maior interferência sobre os cultivares de soja "IAS 5" e "Fepagro RS 10" que estes sobre o nabo. Já a proporção entre plantas de soja de diferentes cultivares não modifica essas relações, apresentando os cultivares "IAS 5" e "Fepagro RS 10" competitividades equivalentes ao "Fundacep 33”, quando crescem juntos.

Há competição por recursos do ambiente entre soja e nabo, mas não ocorre competição do cultivar de soja "Fundacep 33" em relação aos cultivares "IAS 5" e “Fepagro RS 10".

\section{REFERÊNCIAS}

BAUMANN, D.T. et al. Intercropping leeks to suppress weeds. Weed Research, Oxford, v.40, n.4, p.359-374, 2000.

COUSENS, R. Aspects of the design and interpretation of competition (interference) experiments. Weed Technology, Champaign, v.5, n.3, p.664-673, 1991.

COUSENS, R.; O’NEILL, M. Density dependence of replacement series experiments. Oikos, Copenhagen, v.66, n.2, p.347-352, 1993.

CROTSER, M.P.; WITT, W.W. Effect of Glycine max canopy characteristics, G.max interference, and weed-free period on
Solanum ptycanthum growth. Weed Science, Lawrence, v.48, n.1, p.20-26, 2000

GHOSH, P.K. Growth, yield, competition and economics of groundnut/cereal fodder intercropping systems in the semi-arid tropics of India. Field Crops Research, Amsterdam, v.88, n.2-3, p.227-237, 2004.

HOFFMAN, M.L.; BUHLER, D.D. Utilizing Sorghum as a functional model of crop-weed competition. I. Establishing a competitive hierarchy. Weed Science, Lawrence, v.50,n.4, p.466-472, 2002.

JOLLIFFE, P.A. et al. A reinterpretation of yield relationships in replacement series experiments. Journal of Applied Ecology, Oxford, v.21, n.1, p.227-243, 1984.

PANTONE, D.J.; BAKER, J.B. Reciprocal yield analysis of red rice (Oryza sativa) competition in cultivated rice. Weed Science, Champaign, v.39, n.1, p.42-47, 1991.

PASSINI, T. Competitividade e predição de perdas de rendimento da cultura de feijão quando em convivência com Brachiaria plantaginea (Link) Hitchc. 2001. 130f. Tese (Doutorado em Agronomia) - Escola Superior de Agricultura Luiz de Queiroz, Universidade de São Paulo.

PONCE, R.G. Competition between barley and Lolium rigidum for nitrate. Weed Research, Oxford, v.38, n.6, p.453-460, 1998.

PURICELLI, E.C. et al. Spurred anoda (Anoda cristata) competition in narrow- and wide-row soybean (Glycine max). Weed Technology, Lawrence, v.17, n.3, p.446-451, 2003.

RADOSEVICH, S.R. Methods to study interactions among crops and weeds. Weed Technology, Champaign, v.1,n.3, p.190-198, 1987.

RIZZARDI, M.A. et al. Interferência de populações de Euphorbia heterophylla e Ipomoea ramosissima isoladas ou em misturas sobre a cultura de soja. Planta Daninha, Viçosa, v. 22, n.1, p.29-34, 2004.

ROUSH, M.L. et al. A comparison of methods for measuring effects of density and proporcion in plant competition experiments. Weed Science, Champaign, v.37, n.2, p.268275, 1989.

SAS Institute Statistical Analysis System. User's guide. 4.ed. Cary: SAS Institute, 1989. 846p.

VILÀ, M. et al. Competition experiments on alien weeds with crops: lessons for measuring plant invasion impact? Biological Invasions, Dordrecht, v.6, n.1, p.59-69, 2004 